\title{
Preparation of Platinum Nanoparticles-Graphene Modified Electrode and Selective Determination of Rutin
}

\author{
Shu-Hong Yu and Guang-Chao Zhao \\ School of Chemistry and Materials Science, Anhui Normal University, Wuhu 241000, China \\ Correspondence should be addressed to Guang-Chao Zhao, gczhao@mail.ahnu.edu.cn \\ Received 31 January 2011; Revised 24 March 2011; Accepted 5 April 2011 \\ Academic Editor: Rene Kizek
}

Copyright ( $) 2012$ S.-H. Yu and G.-C. Zhao. This is an open access article distributed under the Creative Commons Attribution License, which permits unrestricted use, distribution, and reproduction in any medium, provided the original work is properly cited.

\begin{abstract}
Platinum nanoparticles were electrodeposited on graphene modified glassy carbon electrode to form a modified electrode, and the electrode was characterized with scanning electron microscopy (SEM). At the modified electrode, rutin, a natural flavonoid, shows a couple of well-defined redox peaks, which is corresponded to the reduction and reoxidation of rutin. The electrochemical behaviors of rutin at the electrode were investigated, and the results indicated that the electrode reaction is controlled by adsorption process. Under the optimal conditions, the peak currents of differential pulse voltammetry (DPV) increased linearly with the rutin concentration in the range from $2.0 \times 10^{-8}$ to $8.0 \times 10^{-5} \mathrm{M}$ with a limit of detection of $6.7 \times 10^{-9} \mathrm{M}$. The as-prepared electrode was successfully used for the selective determination of rutin in tablet, displaying a potential application of graphene composite modified electrode.
\end{abstract}

\section{Introduction}

Rutin (quercetin-3-rutinoside, which chemical structure is shown in Figure 1) is a natural flavonoid with a wide of biochemical and pharmacological activities, including antigenotoxic, anti-inflammatory, antioxidant effects, antibacterial, antiviral, cytoprotective, and antiprotozoal properties, hypolipidaemic and anticonvulsive effects, and anticarcinogenic [1-6]. The interest in using rutin in cosmetic and pharmaceutical formulations is to enhance their antioxidant and vasoprotective properties, promoting relief of the symptoms of lymphatic and venous insufficiency. Up to now, methods for investigation of rutin have included spectrophotometry [7], capillary electrophoresis [8], chemiluminescence [9], HPLC [10], and electrochemical methods $[11,12]$. Among these methods, electrochemical method is simple and sensitive. However, the sensitivity and selectivity of electrochemical method usually depends on the electrode material.

Metal nanoparticles have attracted considerable attention due to their conspicuous physical and chemical properties $[13,14]$. Previous investigates suggested that platinum nanoparticles have a good electrocatalytic activity among metal nanoparticles. So, platinum nanoparticles have widely been applied in many fields, such as electrocatalytic oxidation of formic acid and methanol $[15,16]$. However, in order to utilize its function, platinum nanoparticles must be immobilized on supported materials, such as carbon materials and other conducting or semiconducting materials. Graphene is a new form of carbon material with carbon atoms parked in a two-dimensional honey lattice, which has attracted a tremendous amount of attention due to their extraordinary physical, chemical, and mechanical properties. The unique nanostructure and properties of graphene provide potential applications in synthesizing nanocomposites $[17,18]$ and fabricating various microelectrical devices, such as battery [19], field-effect transistors [20], and ultrasensitive sensors [21]. In recent years, graphenebased composites had been used as electrode material to construct electrochemical sensors and biosensors [22, 23]. For example, grapheme/palladium nanocomposite [24] could be used to prepare hydrogen sensor, nitrogen-doped graphene [25] was used for constructing glucose sensor, and graphene/AuNPs/chitosan nanocomposite was used as electrode material to realize glucose biosensing. 


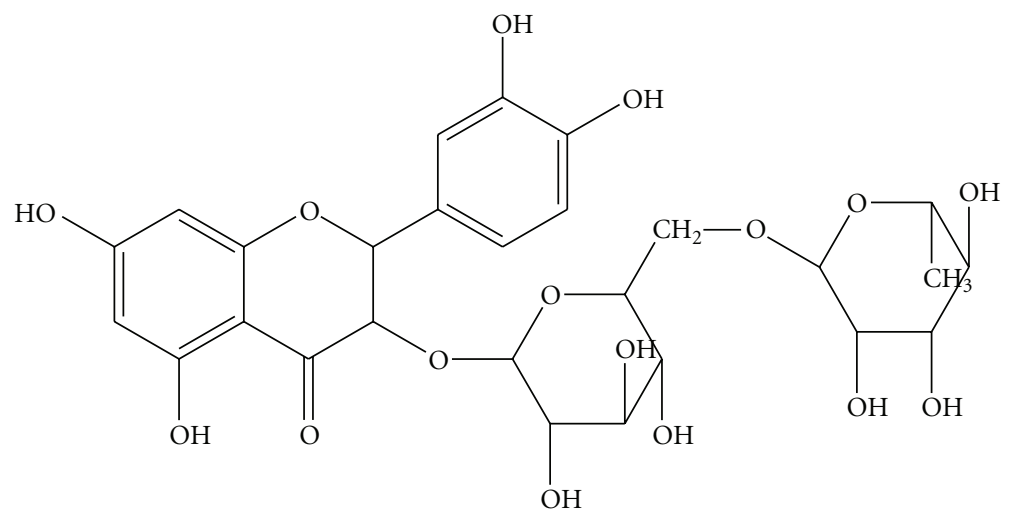

FIGURE 1: Rutin chemical structure.

In this paper, chemically reduced graphene was used as electrode material to construct a graphene electrode. Then, platinum nanopaticles were electrodeposited on this electrode surface to form a Pt nanoparticles/graphene modified electrode. The modified electrode shows a good electrocatalytic activity towards the redox of rutin. Based on this, an electrochemical method for rutin determination was constructed.

\section{Experimental}

2.1. Apparatus and Chemicals. All electrochemical experiments were carried out in a three-electrode cell controlled by $\mathrm{CHI}$ 660B electrochemical workstation (CHI, USA). $\mathrm{Pt} / \mathrm{GR} / \mathrm{GC}$ electrode was used as the working electrode. An $\mathrm{Ag} / \mathrm{AgCl}$ electrode and a platinum wire electrode were used as the reference and the auxiliary electrodes, respectively. S-4800 Scanning Electron Microscopy (Hitachi, Japan) was used for the characterization of electrode surface. Graphite, hydrazine hydrate solution, (50 wt\%) was purchased from Shanghai Chemical Reagent Co., Ltd. 2\% Chitosan (from Sigma) solution was prepared by dissolving Chitosan in $1 \%$ acetic acid solution with magnetic stirring for $2 \mathrm{~h}$. Rutin and $\mathrm{H}_{2} \mathrm{PtCl}_{6} \cdot 6 \mathrm{H}_{2} \mathrm{O}$ were purchased from Shanghai Reagent Factory. Unless otherwise stated, reagents were of analytical grade and used as received. All aqueous solutions were prepared with doubly distilled water. All electrochemical experiments were carried out at room temperature.

2.2. Synthesis of Graphene. Graphene used in this experiment was prepared through chemically reducing graphene oxide. Graphene oxide was synthesized from graphite according to Hummers and Offeman's method [26]. The preparation of graphene from graphene oxide can be described as follows: (1) the synthesized graphene oxide was dispersed in water to create a $0.08 \%$ (wt $\%$ ) aqueous solution. Then, $1 \mathrm{~mL}$ of $2 \%$ chitosan (CS) was added into $2 \mathrm{~mL}$ above solution, and the solution was mixed by ultrasonication for $30 \mathrm{~min}$ to form a lightly yellow dispersion. $40 \mu \mathrm{L}$ hydrazine hydrate solution was added to the lightly yellow solution. The mixture was stirred for $5 \mathrm{~min}$ and reacted at $100^{\circ} \mathrm{C}$ for $24 \mathrm{~h}$. In the end of the reaction, the color of mixture solution changed from lightly yellow to black, indicating the reduction of graphene oxide. The black CS-dispersed graphene aqueous solution is stable for four weeks at room temperature.

2.3. Preparation of Pt/GR/GC Modified Electrode. The bare glassy carbon electrode was polished with emery paper and alumina slurries $(0.3 \mu \mathrm{m}$ and $0.05 \mu \mathrm{m})$. Then, it was thoroughly rinsed with water and sonicated in acetone and water (each for $5 \mathrm{~min}$ ). $10 \mu \mathrm{L}$ of CS-dispersed graphene solution was dropped onto a GC electrode surface, and the electrode was allowed to dry in ambient air for $24 \mathrm{~h}$ to form a CS-graphene modified electrode, noted as GR/GC electrode. Then, the GR/GC modified electrode was soaked in $1.0 \times 10^{-3} \mathrm{M} \mathrm{H}_{2} \mathrm{PtCl}_{6}$ solution. Platinum nanoparticles were electrodeposited on the graphene electrode surface to form a Pt/GR/GC electrode through applying a potential of $-0.2 \mathrm{~V}$ (versus $\mathrm{Ag} / \mathrm{AgCl}$ ) and continuing time of $20 \mathrm{~s}$. The electrode was rinsed and kept in refrigerator at $4^{\circ} \mathrm{C}$ before used. Correspondingly, Pt/GC was prepared according to above mentioned process without graphene.

\section{Results and Discussion}

3.1. SEM Characterization of Graphene and Pt/GR/GC Electrode. The morphologies of graphene oxides, graphene, and Pt/graphene on electrode surface were observed by SEM. Figure 2 shows the typical SEM images of electrode surface covered with graphene oxide, graphene, and Pt nanoparticle/graphene, respectively. From Figure 2(a), the graphene oxide film looks like a thin wrinkled paper on electrode surface. From Figure 2(b), the CS-dispersed graphene film shows a clear flake-like shape, which is significantly different from that of the graphene oxide. Additionally, the irregular shapes of graphene through a simple casting method on GC electrode exhibit a layer structure. From Figure 2(c), it can be seen that those white dots, which are platinum nanoparticles, were uniformly dispersed on graphene surfaces. It indicated that Pt/GR/GC modified electrode was successfully prepared.

3.2. Electrochemical Response of Rutin on Pt/GR/GC Electrode. Figure 3 shows the typical cyclic voltammograms (CVs) of 


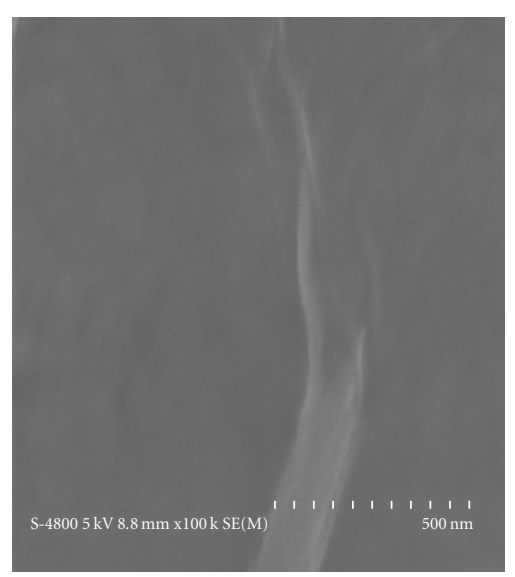

(a)

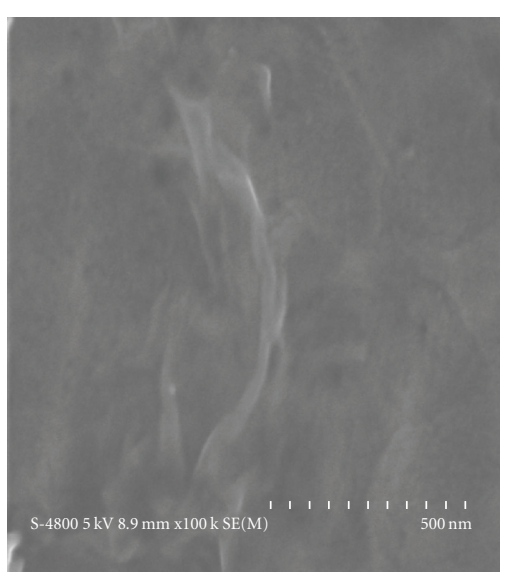

(b)

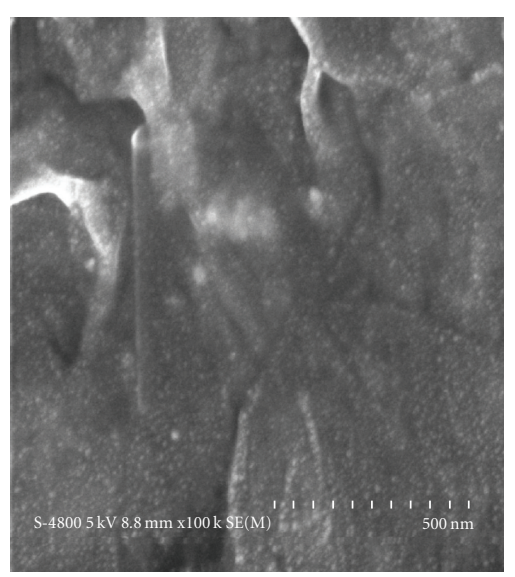

(c)

FIgURE 2: SEM image of (a) graphene oxide, (b) graphene, and (c) platinum nanopaticles on graphene.

rutin at different electrode in $\mathrm{pH} 5.0$ phosphate buffer solution. As can be seen from Figure 3, a couple of well-defined redox peaks was observed at all four electrodes, which corresponds to the reduction and reoxidation of rutin. The cathodic and anodic peak potentials were about at $0.357 \mathrm{~V}$ and $0.420 \mathrm{~V}$ (versus $\mathrm{Ag} / \mathrm{AgCl}$ ). Among the four electrodes, $\mathrm{Pt} / \mathrm{GR} / \mathrm{GC}$ electrode gave the highest peak current. Both cathodic and anodic peak currents are about 15, 10, and 5 times higher than that of bare GC, Pt/GC, and GR/GC electrodes, respectively, as shown in inset of Figure 3. It can be concluded that the composite of graphene and $\mathrm{Pt}$ nanoparticle provides more active sets for the direct electron transfer between rutin and electrode. It is possible that graphene may play a primary important action, which has larger surface areas and can adsorb easily rutin molecules. The hydroxyl groups of rutin on the graphene surface were catalytically oxidized to corresponding o-quione by platinum nanoparticles on the surface of graphene. So, it makes more sensitive response on $\mathrm{Pt} / \mathrm{GR} / \mathrm{GC}$ electrode than on other electrodes.

Electrochemical behaviors of rutin on the Pt/GR/GC electrode were also investigated. Firstly, we examined the effect of $\mathrm{pH}$ of supporting electrolyte in the range from 4.0 to 8.0. 0.1 M phosphate buffer solution selected as supporting electrolyte. When the $\mathrm{pH}$ of supporting electrolyte changed in the range of 4.0 8.0, a couple of redox peaks could still be observed but both cathodic and anodic peak potentials were shifted to negative direction. Further experimental results suggested that the formal potential of rutin is dependent linearly on $\mathrm{pH}$ of supporting electrolyte with a slope of $49.0 \mathrm{mV} / \mathrm{pH}$, revealing that proton takes part in the electrode reaction of rutin. Among above $\mathrm{pH}$ range, in pH 5.0 supporting electrolyte, better sensitivity and peak profile were obtained. Thus, $\mathrm{pH}$ 5.0, $0.1 \mathrm{M}$ phosphate buffer solution was selected as supporting electrolyte for further experiments.

Secondly, we studied the effect of scan rate on redox peaks of rutin. With increasing the scan rates, both the anodic peak current and the cathodic peak current are

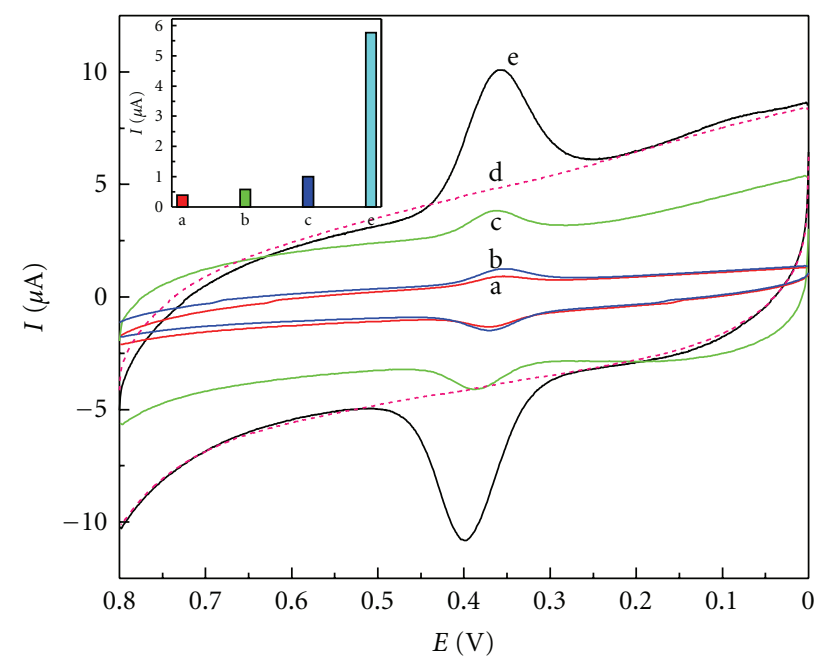

Figure 3: Typical CVs of (a) bare GC, (b) Pt/GC, (c) GR/GC, and (e) $\mathrm{Pt} / \mathrm{GR} / \mathrm{GC}$ electrode in $0.1 \mathrm{M}$ pH 5.0 phosphate buffer solution containing $5 \mu \mathrm{M}$ rutin. (d) $\mathrm{CV}$ of Pt/GR/GC electrode in $0.1 \mathrm{M} \mathrm{pH}$ 5.0 phosphate buffer solution without Rutin. Inset: comparison of anodic peak currents obtained in $5 \mu \mathrm{M}$ rutin solution at different electrodes.

linearly proportional to the scan rates in the range form 10 to $250 \mathrm{mV} / \mathrm{s}$. The anodic peak potentials shift in gradually positive direction and the cathodic peak potentials shift in negative direction. The results indicate that the electrode reaction of rutin is controlled by adsorption process.

3.3. Electrochemical Determination of Rutin. In order to obtain higher sensitivity, differential pulse voltammetry (DPV) was used to determine rutin. Figure 4 records the DPV curves of different concentration of rutin at Pt/GR/GC modified electrode. As can be seen, the DPV peak current increased linearly with rutin concentration. A good linear relationship between the peak current and rutin concentration in the range of $2.0 \times 10^{-8}$ to $8.0 \times 10^{-6} \mathrm{M}$ has been 
TABle 1: Comparison of different electrodes for rutin determination.

\begin{tabular}{lccc}
\hline $\begin{array}{l}\text { Electrode } \\
\text { material }\end{array}$ & Linear range $(\mathrm{mol} / \mathrm{L})$ & $\begin{array}{c}\text { LOD } \\
(\mathrm{mol} / \mathrm{L})\end{array}$ & Reference \\
\hline $\begin{array}{l}\text { gilo/Chi/ } \\
\text { epichlorohydrin }\end{array}$ & $3.4 \times 10^{-7} \sim 7.2 \times 10^{-6}$ & $2.0 \times 10^{-8}$ & {$[28]$} \\
SWNCTs/Au & $2.0 \times 10^{-7} \sim 5.0 \times 10^{-6}$ & $1.0 \times 10^{-8}$ & {$[29]$} \\
IL/CPE & $4.0 \times 10^{-8} \sim 5.0 \times 10^{-5}$ & $1.0 \times 10^{-8}$ & {$[11]$} \\
Pt/GR/GC & $2.0 \times 10^{-8} \sim 8.0 \times 10^{-5}$ & $6.7 \times 10^{-9}$ & this paper \\
\hline
\end{tabular}

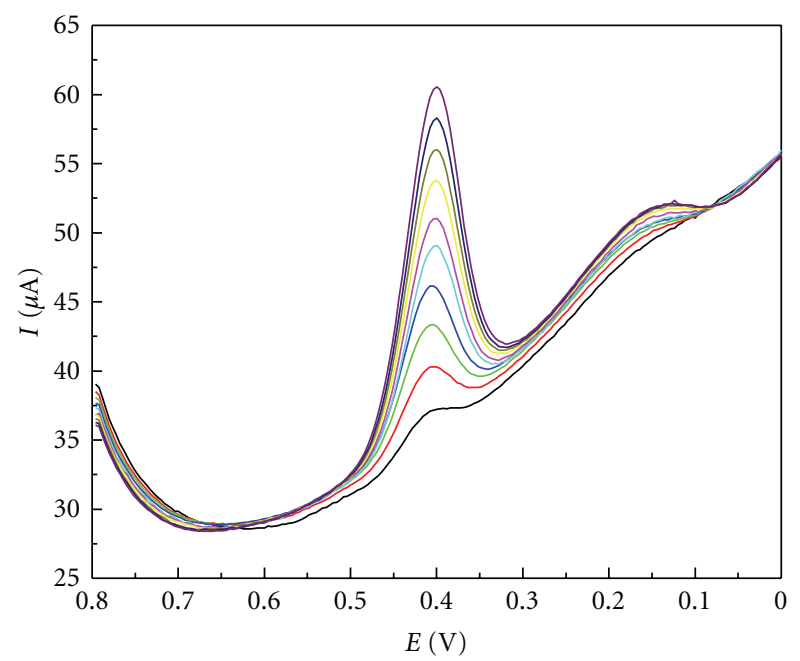

FIGURE 4: DPV curves of different concentrations of rutin in $0.1 \mathrm{M}$ pH 5.0 phosphate buffer solution.

obtained and the correlation coefficient is 0.9998 . The limit of detection (LOD) is $6.7 \times 10^{-9} \mathrm{M}$ at a signal-to-noise ratio of 3. The determination parameters of rutin for this assay were compared with other methods, and the results were listed in Table 1. As can be seen from Table 1, this can provide an assay with wider concentration range and lower LOD. In Figure 4, an unobvious peak at about $0.15 \mathrm{~V}$ was also observed. The previous reported literature suggested that only one DPV peak of rutin can be observed in the presented potential window. According to the literature [27], the small peak at $0.15 \mathrm{~V}$ may be come from thimbleful quercetin, whose structure is similar to rutin and can be as impurity existing in rutin sample.

In experiment, it was observed that $\mathrm{Pt}$ nanoparticles density on the Pt/GR/GC electrode surface can influence on electrochemical response of rutin. Because of the high density $\mathrm{Pt}$ nanoparticles will result in aggregation of nanoparticles and the low density will make the active sites become lack. In order to obtain higher response signal, Pt nanoparticles density was controlled through controlling both the electrolytic time and the concentration of $\mathrm{H}_{2} \mathrm{PtCl}_{6}$. An optimum conditions including $20 \mathrm{~s}$ electrolytic time and $1.0 \times 10^{-3} \mathrm{M} \mathrm{H}_{2} \mathrm{PtCl}_{6}$ was selected to electrodeposit $\mathrm{Pt}$ nanoparticles on graphene.

The repeatability and selectivity of this assay were also investigated. The repeatability of the Pt/GR/GC modified

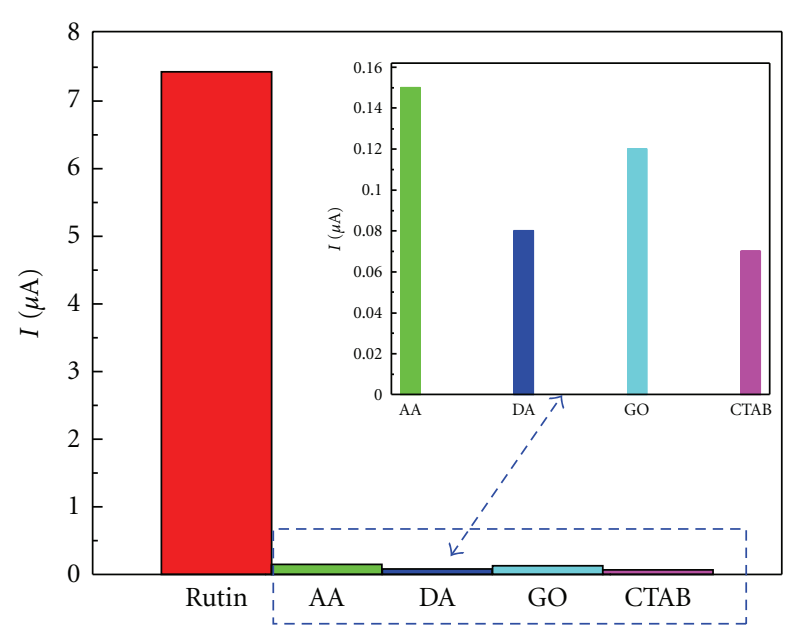

FIGURE 5: Comparison of DPV currents of $1.0 \times 10^{-6} \mathrm{M}$ rutin with $1.0 \times 10^{-3} \mathrm{M}$ outer species in $0.1 \mathrm{M}$ pH 5.0 phosphate buffer solution. The inset is to present other column with lower resolution on $y$ axis.

electrode was evaluated as the following process. The repeatable experiments were performed in $0.1 \mathrm{M} \mathrm{pH} 5.0$ phosphate buffer solution containing $2.0 \times 10^{-6} \mathrm{M}$ rutin. Six-time measurement of peak current was carried out using the same electrode that was refreshed before each measurement. The process for refreshing the electrode can be described as follows: continual CV scans were preformed in a blank pH 7.0 PBS until no redox peak of rutin can be observed [27]. The relative standard deviation was calculated to be $5.1 \%$, indicating that the as-prepared Pt/GR/GC electrode has a good repeatability. In order to study the selectivity, the interference from CTAB, dopamine (DA), ascorbic acid (AA), and glucose (GO) was investigated, and the result was shown in Figure 5. Under the same conditions, the assay of $1.0 \times 10^{-6} \mathrm{M}$ rutin was not interfered with $1.0 \times$ $10^{-3} \mathrm{M}$ above species. The result indicates that the modified electrode can be used to determine rutin in the presence of the amount of outer species and used as a potential tool to analyze factual drug containing rutin with a good selectivity. In addition, the as-prepared Pt/GR/GC modified electrode was stored at room temperature for 4 weeks, and its response current only decreased about $4.5 \%$ comparing with original currents in the same concentration of rutin solution, suggesting that the electrode has long time response stability.

3.4. Determination of Rutin in Tablet. In order to evaluate the applicability of the modified electrode, the rutin in tablet as factual sample was detected. The tablet containing rutin was triturated firstly and dissolved with water. After filtered, the solution was diluted and used as sample to detect rutin directly. According to the experimental conditions, rutin was detected in real samples, and the result was shown in Table 2. No significant difference between the determined result and the marker of label can be observed. In addition, the spiking experiment was carried out. Figure 6 shows the typical voltammograms obtained from the analysis of real 
TABLE 2: Determination of rutin in tablet*.

\begin{tabular}{lcccc}
\hline No. & $\begin{array}{c}\text { Content } \\
(\mathrm{mg} / \text { tablet })\end{array}$ & $\begin{array}{c}\text { Added in } \\
\text { sample } \\
\left(10^{-2} \mathrm{mg} / \mathrm{L}\right)\end{array}$ & $\begin{array}{c}\text { Found in } \\
\text { sample } \\
\left(10^{-2} \mathrm{mg} / \mathrm{L}\right)\end{array}$ & $\begin{array}{c}\text { Recovery } \\
(\%)\end{array}$ \\
\hline 1 & 20.2 & 1.01 & 1.05 & 104 \\
2 & 20.4 & 1.02 & 1.05 & 103 \\
3 & 19.6 & 1.47 & 1.39 & 95 \\
\hline
\end{tabular}

* The marker is $20 \mathrm{mg} /$ tablet.

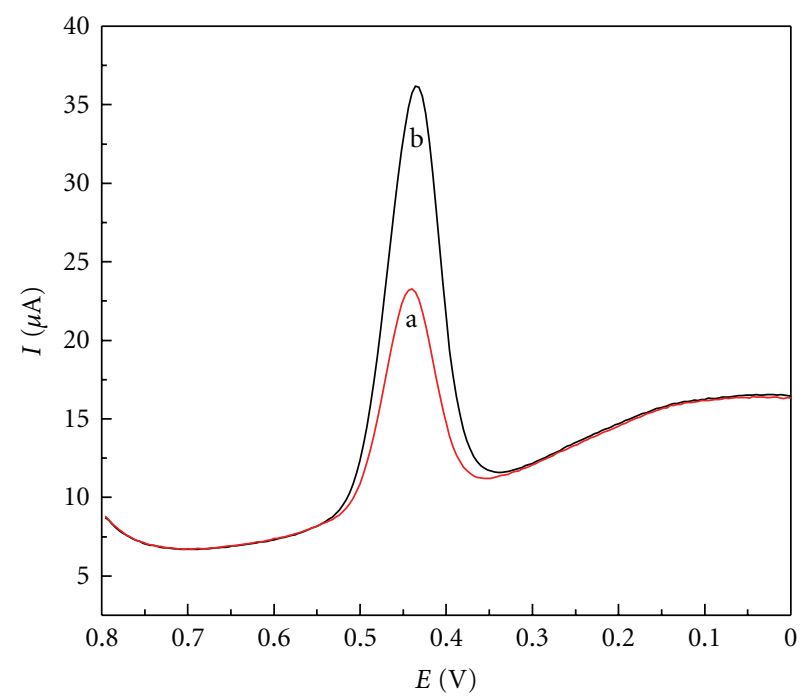

FIGURE 6: Typical CVs of (a) rutin sample (containing $2.6 \mu \mathrm{g}$ Rutin) and (b) a was spiked with $2.6 \mu \mathrm{g}$ rutin in $5 \mathrm{~mL} 0.1 \mathrm{M} \mathrm{pH} 5.0$ phosphate buffer solution.

sample and spiking sample. The experimental results, as recovery, were shown in Table 2. The recovery from 95\% to $104 \%$ shows that the proposed assay is credible. It also suggests that the prepared electrode is suitable for rutin determination in commercial pharmaceutical samples. On the other hand, comparing the assay based on the Pt/GR/GC electrode with other electrodes described in the literature $[11,28,29]$ for rutin determination, our electrode has higher sensitivity, lower detection limit, and wider linear range.

\section{Conclusions}

In this paper, a Pt/GR/GC modified electrode was constructed through directly electrodepositing Pt nanoparticles on the surface of chemically reduced graphene nanosheet modified electrode. The electrode showed a sensitive response to rutin. A simple and sensitive electrochemical method for rutin determination based on the modified electrode was developed. Under optimized conditions, the modified electrode exhibited a good performance in terms of sensitivity, LOD, and linear calibration range. Moreover, the modified electrode shows higher stability and better repeatability, which may foretell the potential applications of graphene as electrode material in the electroanalytical field.

\section{Acknowledgment}

This research was supported financially by the National Nature Science Foundation of China (20975001).

\section{References}

[1] A. A. Ramos, C. F. Lima, M. L. Pereira, M. Fernandes-Ferreira, and C. Pereira-Wilson, "Antigenotoxic effects of quercetin, rutin and ursolic acid on HepG2 cells: evaluation by the comet assay," Toxicology Letters, vol. 177, no. 1, pp. 66-73, 2008.

[2] R. Guo, P. Wei, and W. Liu, "Combined antioxidant effects of rutin and Vitamin C in Triton X-100 micelles," Journal of Pharmaceutical and Biomedical Analysis, vol. 43, no. 4, pp. 1580-1586, 2007.

[3] K. H. Janbaz, S. A. Saeed, and A. H. Gilani, "Protective effect of rutin on paracetamol- and CCl-induced hepatotoxicity in rodents," Fitoterapia, vol. 73, no. 7-8, pp. 557-563, 2002.

[4] S. Y. Park, S. H. Bok, S. M. Jeon et al., "Effect of rutin and tannic acid supplements on cholesterol metabolism in rats," Nutrition Research, vol. 22, no. 3, pp. 283-295, 2002.

[5] M. Nassiri-Asl, S. Shariati-Rad, and F. Zamansoltani, "Anticonvulsive effects of intracerebroventricular administration of rutin in rats," Progress in Neuro-Psychopharmacology and Biological Psychiatry, vol. 32, no. 4, pp. 989-993, 2008.

[6] R. P. Webster, M. D. Gawde, and R. K. Bhattacharya, "Protective effect of rutin, a flavonol glycoside, on the carcinogeninduced DNA damage and repair enzymes in rats," Cancer Letters, vol. 109, no. 1-2, pp. 185-191, 1996.

[7] A. V. Pastukhov, L. A. Levchenko, and A. P. Sadkov, "Spectroscopic study on binding of rutin to human serum albumin," Journal of Molecular Structure, vol. 842, no. 1-3, pp. 60-66, 2007.

[8] Q. H. Lu, C. D. Ba, and D. Y. Chen, "Investigating noncovalent interactions of rutin-serum albumin by capillary electrophoresis-frontal analysis," Journal of Pharmaceutical and Biomedical Analysis, vol. 47, no. 4-5, pp. 888-891, 2008.

[9] D. A. Xu, Z. L. Gao, N. A. Li, and K. E. A. Li, "Tris(2,2'bipyridyl)ruthenium(II) electrochemiluminescence (ECL) enhanced by rutin on platinum electrode," Chinese Chemical Letters, vol. 18, no. 5, pp. 561-564, 2007.

[10] K. Ishii, T. Furuta, and Y. Kasuya, "Determination of rutin in human plasma by high-performance liquid chromatography utilizing solid-phase extraction and ultraviolet detection," Journal of Chromatography B, vol. 759, no. 1, pp. 161-168, 2001.

[11] Y. A. Zhang and J. Zheng, "Sensitive voltammetric determination of rutin at an ionic liquid modified carbon paste electrode," Talanta, vol. 77, no. 1, pp. 325-330, 2008.

[12] A. A. Ensafi and R. Hajian, "Determination of rutin in pharmaceutical compounds and tea using cathodic adsorptive stripping voltammetry," Electroanalysis, vol. 18, no. 6, pp. 579$585,2006$.

[13] X. Dai, O. Nekraseova, M. E. Hyde, and R. G. Compton, "Anodic stripping voltammetry of arsenic(III) using gold nanoparticle-modified electrodes," Analytical Chemistry, vol. 76, no. 19, pp. 5924-5929, 2004.

[14] S. Hrapovic, Y. Liu, and J. H. T. Luong, "Reusable platinum nanoparticle modified boron doped diamond microelectrodes for oxidative determination of arsenite," Analytical Chemistry, vol. 79, no. 2, pp. 500-507, 2007.

[15] Z. H. Wang and K. Y. Qiu, "Electrocatalytic oxidation of formic acid on platinum nanoparticle electrode deposited 
on the nichrome substrate," Electrochemistry Communications, vol. 8, no. 7, pp. 1075-1081, 2006.

[16] S. Palmero, A. Colina, E. Muñoz, A. Heras, V. Ruiz, and J. López-Palacios, "Layer-by-layer electrosynthesis of PtPolyaniline nanocomposites for the catalytic oxidation of methanol," Electrochemistry Communications, vol. 11, no. 1, pp. 122-125, 2009.

[17] Y. Xu, H. Bai, G. Lu, C. Li, and G. Shi, "Flexible graphene films via the filtration of water-soluble noncovalent functionalized graphene sheets," Journal of the American Chemical Society, vol. 130, no. 18, pp. 5856-5857, 2008.

[18] R. Muszynski, B. Seger, and P. V. Kamat, "Decorating graphene sheets with gold nanoparticles," The Journal of Physical Chemistry C, vol. 112, no. 14, pp. 5263-5266, 2008.

[19] T. Cassagneau and J. H. Fendler, "High density rechargeable lithium-ion batteries self-assembled from graphite oxide nanoplatelets and polyelectrolytes," Advanced Materials, vol. 10, no. 11, pp. 877-881, 1998.

[20] S. Gilje, S. Han, M. Wang, K. L. Wang, and R. B. Kaner, "A chemical route to graphene for device applications," Nano Letters, vol. 7, no. 11, pp. 3394-3398, 2007.

[21] F. Schedin, A. K. Geim, S. V. Morozov et al., "Detection of individual gas molecules adsorbed on graphene," Nature Materials, vol. 6, no. 9, pp. 652-655, 2007.

[22] C. Shan, H. Yang, J. Song, D. Han, A. Ivaska, and L. I. Niu, "Direct electrochemistry of glucose oxidase and biosensing for glucose based on graphene," Analytical Chemistry, vol. 81, no. 6, pp. 2378-2382, 2009.

[23] M. Zhou, Y. Zhai, and S. Dong, "Electrochemical sensing and biosensing platform based on chemically reduced graphene oxide," Analytical Chemistry, vol. 81, no. 14, pp. 5603-5613, 2009.

[24] U. Lange, T. Hirsch, V. M. Mirsky, and O. S. Wolfbeis, "Hydrogen sensor based on a graphene-palladium nanocomposite," Electrochimica Acta, vol. 56, no. 10, pp. 3707-3712, 2011.

[25] Y. Wang, Y. Shao, D. W. Matson, J. Li, and Y. Lin, "Nitrogendoped graphene and its application in electrochemical biosensing," ACS Nano, vol. 4, no. 4, pp. 1790-1798, 2010.

[26] W. S. Hummers and R. E. Offeman, "Preparation of graphitic oxide," Journal of the American Chemical Society, vol. 80, no. 6, p. 1339, 1958.

[27] X. Q. Lin, J. B. He, and Z. G. Zha, "Simultaneous determination of quercetin and rutin at a multi-wall carbon-nanotube paste electrodes by reversing differential pulse voltammetry," Sensors and Actuators, B: Chemical, vol. 119, no. 2, pp. 608614, 2006.

[28] I. R. W. Z. de Oliveira, S. C. Fernandes, and I. C. Vieira, "Development of a biosensor based on gilo peroxidase immobilized on chitosan chemically crosslinked with epichlorohydrin for determination of rutin," Journal of Pharmaceutical and Biomedical Analysis, vol. 41, no. 2, pp. 366-372, 2006.

[29] B. Zeng, S. Wei, F. Xiao, and F. Zhao, "Voltammetric behavior and determination of rutin at a single-walled carbon nanotubes modified gold electrode," Sensors and Actuators, B: Chemical, vol. 115, no. 1, pp. 240-246, 2006. 


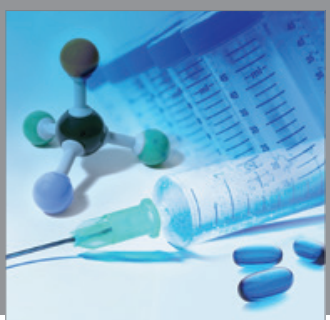

International Journal of

Medicinal Chemistry

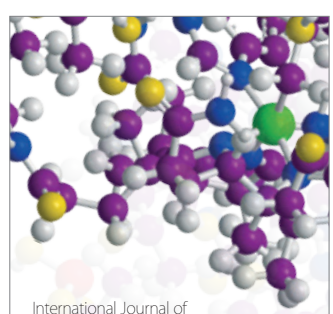

Carbohydrate Chemistry

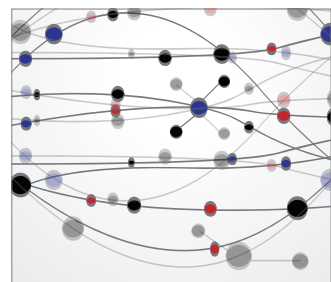

The Scientific World Journal
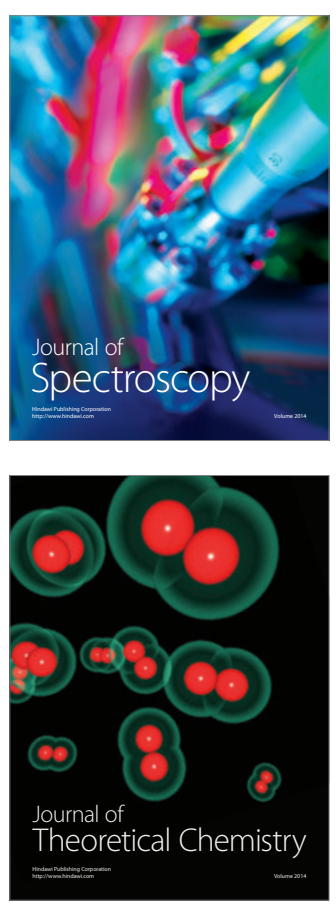
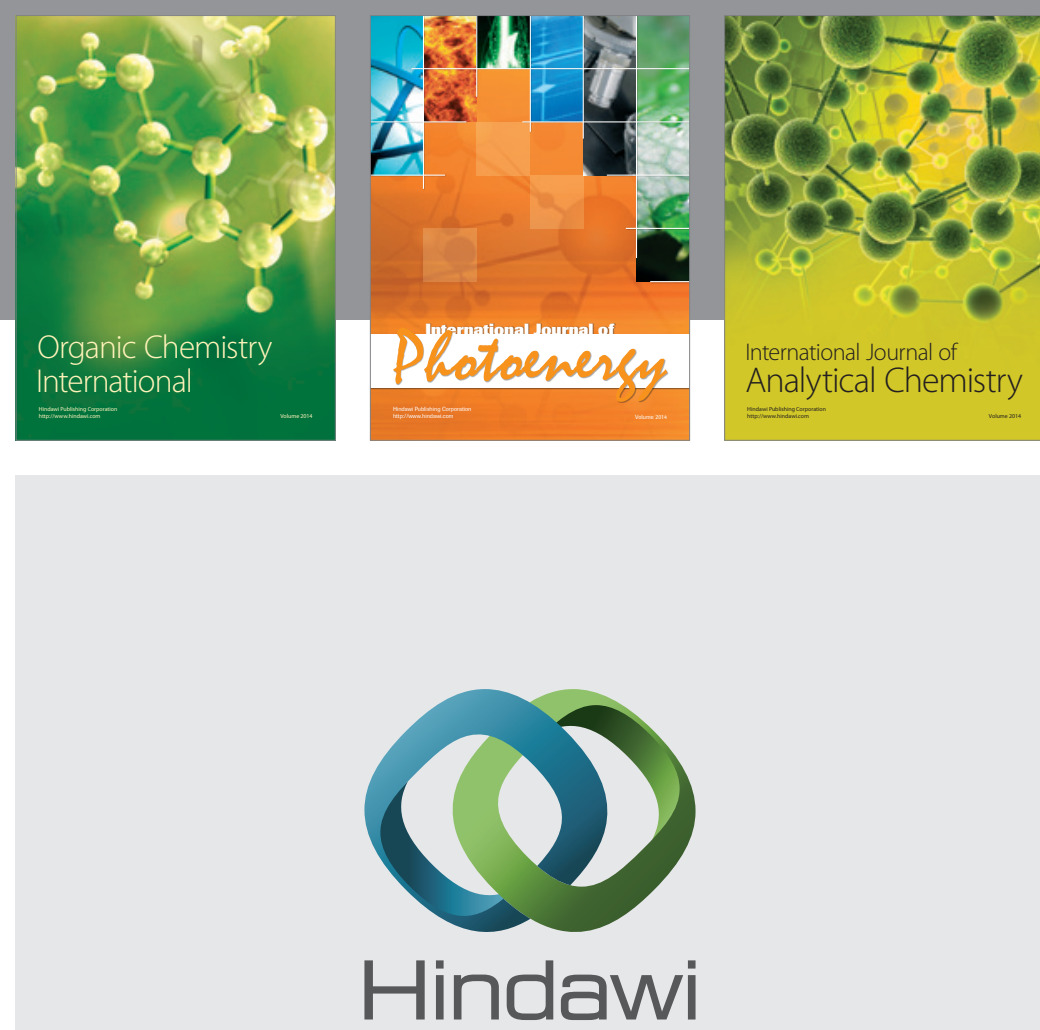

Submit your manuscripts at

http://www.hindawi.com
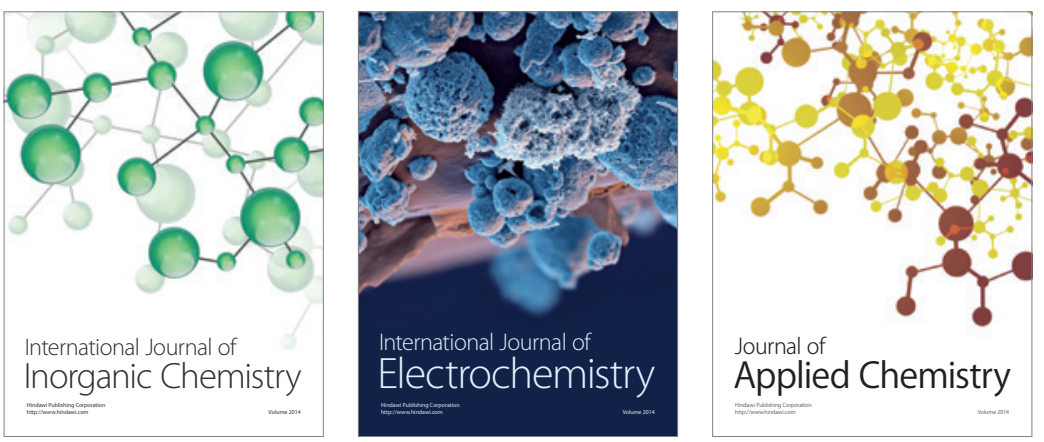

Journal of

Applied Chemistry
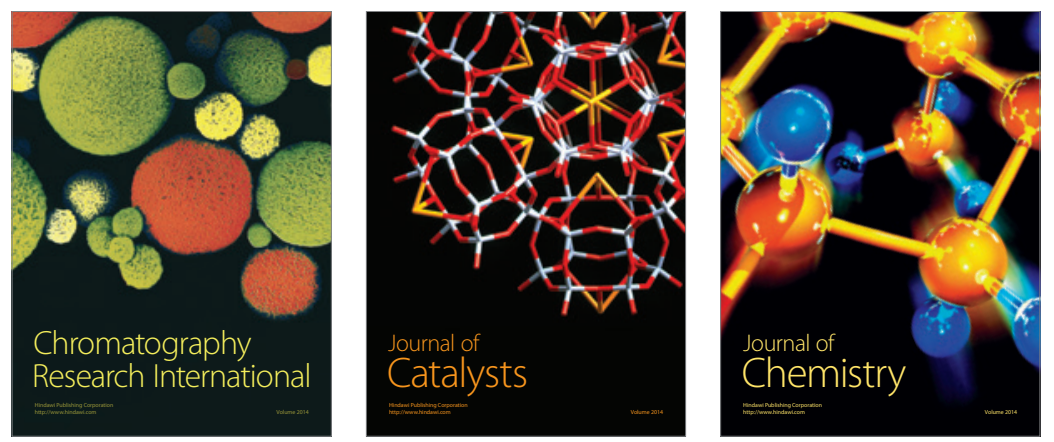
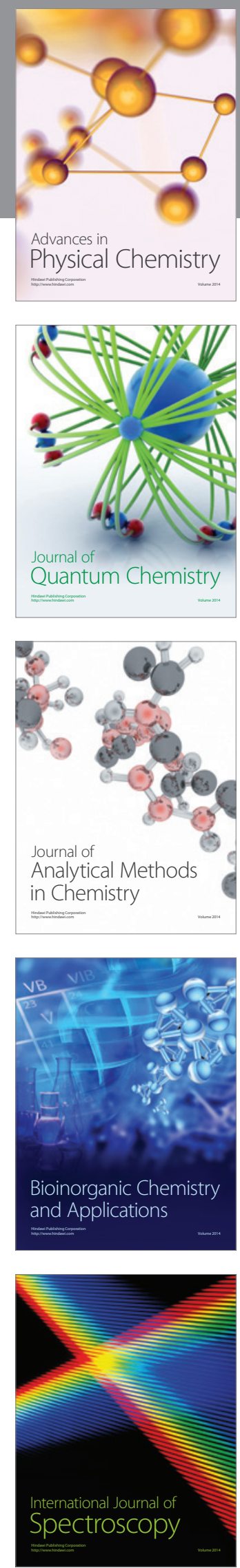